\title{
Knowledge, Beliefs and Attitudes of Health Care Providers towards the Mentally Ill in Delta State, Nigeria
}

\author{
C. Ewhrudjakpor \\ Department of Sociology \& Psychology, Delta State University, P.M.B. 1, Abraka, Nigeria \\ Telephone: 08035784715,08057019970,E-mail: acadchris@yahoo.com
}

KEYWORDS Attitudes. Beliefs. Care Providers. Medical Knowledge. Mental Illness

\begin{abstract}
This study aimed at chronicling the socio-cultural impediments to the favourable dispositional postures of health care providers despite their huge knowledge of the illness towards the mentally sick. 483 respondents with varied demographic characteristics participated. The multi-stage cluster technique was used to select these respondents amongst the health workers in Delta State government owned health institutions. With the aid of a structured questionnaire data was generated that was analyzed using percentages and Chi-square statistic. The findings show that despite the impressive medical knowledge of the illness by health workers, they still harbour deeply rooted cultural beliefs and traditional social acts to dislike the mentally sick. Consequently, robust enlightenment campaigns and workshops are recommended.
\end{abstract}

\section{INTRODUCTION}

The universality of harmful beliefs and subsequent negative attitudes towards the mentally ill is not in doubt (Thara and Srinivasan 2000; Murphy 2002; Botha et al. 2006). This study is set out to identify the persistent socio-cultural factors impeding the acceptability of mentally sick persons in Nigeria, particularly among health care providers in Delta State. The concept of mental health or illness has a problematic definition because it is largely subjective. It can only achieve a near uniformity of meaning in the medical arena although a complete state of mental health or well being is almost impossible to attain. The sufferers of mental illness are part of the society but are viewed differently by the society (C.M.H.A. 1993; Murphy 2002; Paterson 2006). Therefore, societal reaction to the mentally sick varies from society to society, as the culture of a people is also a model for human behaviour.

African societies have a peculiar attitude towards the sick or mentally ill persons and this is evident in the rejection, scornful disposition and a negative perception of the sick individual (Sharma 1998; Mohammed et al. 2004; Mohammed and Mohammed 2008). Mental illness is a disorder of one or more of the functions of the mind such as emotion, perception, memory or thoughts, which causes suffering to the person and embarrassment to the family and society. There are a varied number of mental illnesses but the most common and broader classification is psychoses, neuroses and mental retardation. Mental illness could be spurred by environmental or cultural factors and also, by physiological malfunctioning and heredity, these are referred to as functional and organic psychoses respectively.

Allport (1961) posited that an attitude is "mental and neural state of readiness organized through experience, exerting a dynamic influence upon the individual response to all objects or to situations with which it is related". Similarly (Ewhrudjakpor 1995; Mohammed and Mohammed 2008) defines an attitude as a "learned orientation or disposition, toward an object or situation which provides a tendency to respond favourably or unfavourably to the object or situation". However strong these attitude definitions are, it was (Zimbardo and Ebbesen 1969) that put it in proper structure when they defined it as "a predisposition, toward any person, ideas or objects, it contains cognitive, affective and behavioural components".

Thus, individuals disposition becomes an attitude if it contains in some parts, aspects of knowing and acting. Zimbardo and Ebbesen (1969) further assert that, affective component of our attitude consists of a person's evaluation of liking or emotional response to some objects or person. The cognitive component refers to the way the object or person is perceived. It is in fact the mental picture formed in the individual's 
brain. This includes the person's thoughts, beliefs and knowledge about the object. The behaviour component involves the person's overt acts directed towards another person or group of persons or objects.

Nigerians make attributions in respect of their attitudes towards sufferers of mental illness. They in most cases do this naively (Ugwuegbu 1994). Attribution theory as postulated by (Heider 1958) states the rules people use to infer the causes of observed behaviour. He divides this process into two: dispositional and situational attribution processes. The dispositional attribution is the process where a person's actions is attributed to internal dispositions (attitudes, traits, motives). While situational attribution is attributing a person's actions to factors in the environment such as witchcraft, poverty, beliefs, and so forth.

\section{Statement of Problem}

Mental illness is a diseased condition, which is deemed undesirable for both the affected individual and the society because it affects adversely the normal functioning of the mental, psychological and emotional make-up of the individual and so it makes the capacity for insight, orientation, judgment, thought, mood and perception blurred (WHO 2001; WPA 2002). The mentally sick in Nigeria culture, most traditional communities ought to look after them since they are still a part of the community and there are possible traditional therapeutic regimens to bring them to a relative state of normality (Jegede 1981; Adebowale and Ogunlesi 1999; Gureje et al. 2005). However, in Nigeria the situation is now different as mentally ill individuals are socially stigmatized even after they have been cured of this illness (Jegede 2005; Brinn 2000; Binitie 1970). This is in contrast with the communal and closely-knit kinship system in which each person has a responsibility for the well being of the other which dominated African societies (Ayorinde 1983).

The mentally sick people constitute nuisance since their consciousness is affected, this is why they need treatment and rehabilitation but the Nigerian situation is quite different as government and the family unit have not done much towards their rehabilitation since many mentally sick persons are not taken care of but allowed to become vagrants. Also, health workers who should know better seem not to display positive attitude towards such sick people. There is also the problem of cultural factors, which label such people as evil possessed and witchcraft 'infested'.

Most Nigerians believe that mental illness are afflictions caused by supernatural forces (Udoh 2002). Therefore they hold unorthodox beliefs that only traditional and syncretic religious healers can offer more effective and sustainable treatment than orthodox health practitioners.

Hypothetically, this author shall test whether there is no significant relationship between medical knowledge, cultural beliefs and health workers' attitudes towards the mentally sick.

This study will provide information on the general attitude of Nigerians particularly Delta State health workers towards the mentally sick. Also, it will increase the knowledge of people on mental illness in general and correct all misconceptions about the disease and prompt governments and non-governmental agencies efforts in making more readily available resources for treatment facilities and rehabilitation of mentally ill persons.

\section{METHODS}

Population of Study: This study pertains to health care providers. They include Physicians, Nurses, Social Welfare Officers, Health Assistants and Pharmacists only. This population of professionals was deliberately chosen because they work particularly to give care to the sick, the mentally ill inclusive.

Sample/Sampling Technique: Health care providers designated for this study were five hundred (500) from 44 Hospitals. They were all employees of government owned health institutions (General hospitals, Central hospitals and Cottage hospitals).

The choice of selecting these respondents was based on the fact that, their activities are organized in the unorthodox structure. Therefore, the selection truly represents health care providers in Delta State.

The probability sampling method was used to make the selection of the participants. That is choosing respondents in such a way that the probability of each member of the population being selected can be specified. Specifically the multi-stage cluster sampling technique was used to select the health staff that eventually filledout the structured questionnaire in this study. This technique was chosen because the study population was widely dispersed in the state.

Instrument: A structured questionnaire 
containing three sections was used to gather data from the health staff. It consists of: Section A: Demographic information, Section B: Knowledge and Beliefs of Mental Health and Illness, Section $\mathrm{C}$ : Attitude towards mental ill persons.

The section ' $C$ ' contain Attitude questions. The twenty (20) questions included positive and negative aspects of the illness vis-à-vis the Delta State Community. Thus, positive statements were assigned a scale value of $1,2,0,3,4$, representing these options, which the respondents have to choose one, namely; "Strongly Agreed" "Agreed", "Undecided", "Disagreed", "Strongly Agreed". The other ten statements were negative with the scale value of $4,3,0,2,1$, representing "Strongly disagreed", "disagreed", "undecided", "Agreed" and "Strongly Agreed" respectively.

Procedure of Data Collection: The data were collected based on the knowledge - Belief Attitude concept of health care providers. The researcher sought the assistance of six of his postgraduate students to help administer the questions in their senatorial districts, (three in Delta State: Central, South and North) during their second semester holidays. They were specifically debriefed how to distribute and collect the questionnaires. The questionnaires were distributed using the ratio of: 1:3:2:5:2 (Physicians, Nurses, Social Workers, Health Assistants and Pharmacists.

Altogether, five hundred questionnaires were administered, out of these; four hundred and eighty-three (483) representing $96.6 \%$ was recovered for statistical analysis.

\section{RESULTS AND DISCUSSION}

Out of the 500 questionnaires administered, 483 were properly filled and returned and on this number the statistical analysis is based (Tables $1-4)$.

This section of the research critically evaluates the relationship of the attitudinal dispositions to medical knowledge and beliefs of the respondents. It is effected through the results shown at the rear of the paper succinctly described, critically evaluated and corroborated by related studies as contained in the literature universally.

Demographically, the respondents truly represent the study universe as shown in table 1 . For instance females are more in the unorthodox health profession as in (Ewhrudjakpor 1995) and here they are $72.46 \%$ as against males $27.54 \%$ in

Table 1: Demographic characteristics of respondents $N=483$

\begin{tabular}{|c|c|c|c|c|}
\hline Sex & \multicolumn{2}{|c|}{ No. of Respondents } & \multicolumn{2}{|c|}{ Percentage (\%) } \\
\hline Male & \multicolumn{2}{|c|}{133} & \multicolumn{2}{|c|}{27.54} \\
\hline Female & \multicolumn{2}{|c|}{350} & \multicolumn{2}{|c|}{72.46} \\
\hline Total & \multicolumn{2}{|c|}{483} & \multicolumn{2}{|c|}{100.00} \\
\hline Age & Male & Female & Sub-total & Percentage (\%) \\
\hline $20-30$ & 4 & 14 & 18 & 3.73 \\
\hline $30-40$ & 7 & 8 & 16 & 3.54 \\
\hline $40-50$ & 66 & 121 & 187 & 38.72 \\
\hline $50-60$ & 7 & 8 & 8 & 18.22 \\
\hline $60-70$ & 5 & 6 & 28 & 5.80 \\
\hline Total & 133 & 350 & 483 & 100.00 \\
\hline Occupation & Male & Female & Sub-total & Percentage (\%) \\
\hline Physicians & 8 & 10 & 18 & 3.73 \\
\hline Nurses & 60 & 102 & 162 & 33.54 \\
\hline Social welfare & 23 & 64 & 87 & 18.01 \\
\hline Pharmacists & 6 & 32 & 38 & 7.87 \\
\hline Orderlies Health Assistants & 36 & 142 & 178 & 36.85 \\
\hline Total & 133 & 350 & 483 & 100 \\
\hline Marital Status & Male & Female & Sub-total & Percentage (\%) \\
\hline Single & 92 & 35 & 127 & 26.29 \\
\hline Married & 121 & 226 & 347 & 71.84 \\
\hline Divorced & 2 & 7 & 9 & 1.86 \\
\hline Total & 133 & 350 & 483 & 100.00 \\
\hline
\end{tabular}


Table 1: Contd...

\begin{tabular}{|c|c|c|c|c|}
\hline Religion & Male & Female & Sub-total & Percentage (\%) \\
\hline Christianity & 102 & 330 & 432 & 89.44 \\
\hline Islam & 8 & 6 & 14 & 2.90 \\
\hline ATR African Traditional Religion & 23 & 14 & 37 & 7.66 \\
\hline Total & 133 & 350 & 483 & 100.00 \\
\hline Ethnic Group & Male & Female & Sub-total & Percentage (\%) \\
\hline Urhobo & 99 & 34 & 133 & 27.54 \\
\hline Itsekiri & 47 & 51 & 98 & 20.29 \\
\hline Izon & 22 & 13 & 35 & 7.25 \\
\hline Isoko & 68 & 40 & 108 & 22.36 \\
\hline Ibo (Ukwuani) & 63 & 46 & 109 & 22.56 \\
\hline Total & 299 & 184 & 483 & 100.00 \\
\hline
\end{tabular}

this study. This is corroborated by the occupational representation where Social welfare officers: $18.01 \%$, Nurses $33.54 \%$ and Health Assistants; $36.85 \%$ made clear difference between females and males. These three occupations are in Nigeria dominated by females. These are the real care and hospitality staff amongst medical staff, because others like physicians and pharmacists are technical staff and are predominantly concerned with chemotherapeutic and physical treatment of patients.

Subsequently, it is expected that these seeming professional care givers will acquire knowledgemedical and cultural to accentuate chemotherapeutically and psychologically the physical, emotional and social pains of the mentally sick. Table 2 shows clearly that the respondents in this study do have huge medical knowledge but anachronistic beliefs still deeply held about mental illness and its sufferers. This result corroborates earlier studies (Mohammed et al. 2004; Gureje et al. 2005). For instance $60.25 \%$ source of knowledge is from reading textbooks. $62.94 \%$ of respondents believe that mental illness is caused by consumption of hard drugs. They all truly know symptoms associated with what they refer to as 'kolo' in the state among youths. Consequent upon these, $87.16 \%$ respondents believe that mental illness is incurable and that the end result is death, which begins from stigmatization and loss of their beloved. This confirmed the studies by (Murphy 2002; Paterson 2006). Unfortunately most of these respondents do not physically support the mentally sick, instead they $(34.04 \%)$ prefer to pray for them. In fact $41.82 \%$ say they would shun or reject out rightly family members suffering from mental illness. This supports the study done by (Thara and Srinivasan 2000; Murphy 2002; WPA 2002; Jegede 2005).
Table 2: Knowledge and beliefs of Health Staff about Mental illness $(N=483)$

\begin{tabular}{|c|c|c|}
\hline Particulars & $\begin{array}{l}\text { No. of } \\
\text { responses }\end{array}$ & $\begin{array}{c}\text { Percentage } \\
(\%)\end{array}$ \\
\hline \multicolumn{3}{|l|}{ Source(s) of Information } \\
\hline Reading Books & 291 & 60.25 \\
\hline Workshops/Seminars & 06 & 1.24 \\
\hline Media & 11 & 2.28 \\
\hline Co-staff & 31 & 6.42 \\
\hline Know of Patients & 144 & 29.81 \\
\hline \multicolumn{3}{|l|}{ Cause(s) of Mental illness } \\
\hline Hereditary & 36 & 7.45 \\
\hline \multicolumn{3}{|l|}{ Hard Drugs e.g. Marijuana, } \\
\hline Cocaine, Heroine & 304 & 62.94 \\
\hline Poverty & 00 & 00.00 \\
\hline Curse/Punishment & 69 & 14.29 \\
\hline Witches/Wizards & 74 & 15.32 \\
\hline \multicolumn{3}{|l|}{ Signs and Symptoms } \\
\hline Violence & 41 & 8.49 \\
\hline Irrational acts & 62 & 12.84 \\
\hline Dirty/Uncleanliness & 193 & 39.96 \\
\hline Inappropriate behaviour & 22 & 4.55 \\
\hline Loss of contact with reality & 59 & 12.21 \\
\hline Shamelessness & 106 & 21.95 \\
\hline \multicolumn{3}{|l|}{ Consequences of Mental Illness } \\
\hline Death & 381 & 78.88 \\
\hline Loss of loved ones & 82 & 16.98 \\
\hline Stigmatization & 20 & 4.14 \\
\hline \multicolumn{3}{|l|}{ Curability of Mental Illness } \\
\hline Curable & 62 & 12.84 \\
\hline Incurable & 421 & 87.16 \\
\hline Do not know & 00 & 00.00 \\
\hline \multirow{2}{*}{\multicolumn{3}{|c|}{$\begin{array}{l}\text { Response to Family Member/ } \\
\text { Friend who has Mental Illness }\end{array}$}} \\
\hline & & \\
\hline Supportive & 20 & 4.14 \\
\hline Shun/Rejection & 202 & 41.82 \\
\hline Prayers & 261 & 54.04 \\
\hline \multicolumn{3}{|l|}{ Ethnic Beliefs } \\
\hline Evil doer & 355 & 73.50 \\
\hline Normal ill health & 00 & 00.00 \\
\hline Ostracized & 33 & 6.83 \\
\hline Witch/wizard & 74 & 15.32 \\
\hline Taboo & 21 & 4.35 \\
\hline
\end{tabular}

Relatedly, Delta State as multi-religious and multi-ethnic thus, a mini-Nigeria, the five major ethnic groups (Urhobo, Ibo, Izon, Isoko and 
Itsekiri) culturally believe that these sick persons were evildoers either as witches or wizards or as voodooists or mischief makers. These beliefs as archaic and orthodoxical as they are, are strongly and deeply held by these respondents (73.50\%) in this $21^{\text {st }}$ century. This is the problem. This is the 'roadblock' to wholistic treatment of the mentally sick in this part of the world. This is correlated in table 3 showing the attitudinal disposition of these care providers towards the mentally sick persons (Jegede 1981; Ayorinde 1983; Brinn 2000; Botha et.al 2006; Mohammed and Mohammed 2008) corroborates this result in their researches.

Table 3: Attitude Scores (Summed) of Respondents towards the Mentally Sick. $N=483$.

\begin{tabular}{lccc}
\hline Attitude & $\begin{array}{c}\text { No. of } \\
\text { respondents }\end{array}$ & $\%$ & $\begin{array}{c}\text { Responses } \\
\text { (summed scores) }\end{array}$ \\
\hline Care & 20 & 4.14 & 35 \\
Physical & & & 1450 \\
$\quad$ Maltreatment & 296 & 61.28 & 896 \\
Dangerous & 167 & 34.58 & 2381 \\
\hline Total & 483 & 100.00 & 2 \\
\hline
\end{tabular}

The fact that $296(61.28 \%)$ show that attitudes towards the mentally sick is physical maltreatment, had an attitudinal aggregated score of 1450 . Only $20(4.14 \%)$ respondents opined care with an attitude score of 35 , much more below this studies stated expected attitude mean score of 161 , is a strong indication that health care providers attitude is negative. This confirms earlier studies (Adebowale and Ogunlesi 1999; Jegede 2005). However, to strengthen this finding, the researcher, also subjected the knowledge factors' scores and the attitudinal scores to an inferential statistical technique of chi-square as shown in (Table 4 ).

The Chi-square $\left(\chi^{2}\right)$ calculated is 27.63 which is greater than the critical value of 9.49. The null hypothesis is therefore rejected. That is health care providers do have negative attitudes towards mental illness, therefore their medical knowledge do not determine their attitudes towards the mentally ill. This is not a cheering finding, although it supports studies (WPA 2002; Paterson 2006; Mohammed and Mohammed 2008 reviewed in the current literature. Let us situate this in the concepts of attitude and attribution as defined earlier on.

The cognitive component is the arrowhead of attitude formation. And this can be traced to the culture of a people, which are transmitted through socialization and invariably direct the emotional and conative aspects of the individual's attitude. Most societies in Nigeria see mental illness as a deviation from normality and therefore see mentally sick people as dangerous, outcasts and should be quarantined, this was also reported in earlier studies (WPA 2002; Udoh 2002; Paterson 2006).

The causal attribution that these caregivers show to mental illness is both dispositional and situational but the fact remains that mentally ill persons are disliked. For instance, it is dispositional attribution if the sickness is caused by the individual's excessivenesses and recklessness like in the consumption of alcohol, smoking of marijuana and so forth. while it is situational if it is associated with the evil machination of enemies through witchcraft activities like food poisoning or voodoo attack.

Contemporary analysis of the concept of mental illness in Africa suggests that most Africans believe that the disorder is caused by activities of enemies, spirits, magical practices of sorcerers, curses and witchcraft as seen in this present study (Adebowale and Ogunlesi 1999; Ugwuegbu 1994) in an exploratory study of defensive attribution and attitude to mental illness among class 5 pupils across three ethnic groups of Edo, Ibo and Yoruba. He observed like this present writer that there were subjects who had a high fear for mental illness believing that the mentally ill was to be held responsible for their situation than the low fear subjects. That is, there is a high tendency to hold the mentally sick responsible for his illness. They disagreed that mental illness is like any other illness. This is evident in the discrimination against them and

Table 4: Chi-square Analysis showing the relationship between knowledge and Attitude of health Staff towards the mentally ill.

\begin{tabular}{lcccccc}
\hline Event & (fo) Observed & (fe) Expected & $\chi^{2}$ Calculated & Critical & $D F$ & Inference \\
\hline Positive & 47 & 161 & 27.63 & 9.49 & 4 & $<.05$ Significant \\
Negative & 297 & 161 & & & & \\
Indifferent & 139 & 161 & & & & \\
\hline Total & 483 & 483 & & & \\
\hline
\end{tabular}


their exclusion from social activities and from conventional general hospitals.

Binitie (1970), in his study of 100 persons in Benin City reported that most of the people surveyed have recognized the difference between mild and aggressive mentally ill patients. It was discovered that they (sample) did not consider spirit possession, alcoholism or epilepsy as mental disorder. The mentally ill were associated and recognized with certain features like aggressiveness, nudity, dirt and senseless behaviour. This is the point of resemblance to this present study. It is saddening. The research showed that illiterate Nigerians were more willing to enter into relationship with mentally sick people since it is largely believed that supernatural forces cause the illness and the removal or placation of such forces could restore normality.

Health workers are part of the society. They have been ingrained with their respective cultures and therefore, health workers irrespective of their professional training still do not display a considerably positive attitude towards the mentally sick. Health workers hold mentally ill patients in suspicion even when they are positively responding to treatment or are totally cured as they attribute any irrational act to his formal state of illness. Also, more worrisome is the fact that the societies have labeled them abnormal both in their sickness and even after restoration to normality.

Health workers attitude towards the mentally ill persons is particularly on the negative side as these individuals are known to have lost their memory and are unable to apply reason in their action. The aftermath of this is a social distance between health workers and mentally ill patients since they exhibit unpredictable behaviour, which could be violent, and this contradicts the workers' need for safety.

Brinn (2000) noted that having a mental health problem often carries with it a stigma and the healthcare professionals are not immune to feeling negatively disposed towards such patients. CMHA (1993) cited evidence from a study commissioned by the mental health charityMIND, which found that in the eyes of the general public, '...madness equate with violence'. Therefore, a fear of aggression could often lead to avoidance of mentally ill clients. Studies (Jegede 1981; Jegede 2005) have shown that nurses are now facing increasing violence from patients particularly as certain types of mental disorders e.g. paranoid schizophrenia is associated with aggression mentioned above, past experiences affect our attribution and subsequent behaviour. Stigmatization occurs in the caring professions because it serves to rationalize the avoidance of a patient who is somehow different. As demonstrated by the studies, increasing the psychological components of general health workers training and indepth training will make them express increased positive attitude towards patients (Brinn 2000).

This author believes that each of us needs proper information to put mental illness in the correct perspective. This is because there is a lot of misconception and misinformation in our society about mental illness. The fear of mental illness is deep rooted and it is largely irrational which gained its roots in the dark ages when mental illness was seen to be the devil and therefore the exorcists physically tortured the mentally ill to drive the evil spirit out of their bodies. For instance several women who were mentally sick were branded as 'witches' and were ceremonially burnt on the village squares, ironically, as an act of kindness to save their souls. Today in Europe and North America mentally ill people receive treatment that is far more humane, but here in Nigeria, they are still of the stone age, for instance in Delta State it is the concern of the Ministry of Women Affairs, Community and Social Development. The Ministry in 2006 has successfully gathered the vagrant psychotics together and quarantined them with the help of orthodox native doctors. Where these patients are systematically cared for traditionally until they pass out.

A global survey of attitudes towards mental illness indicates that, even in developed societies, 70 percent of people think that the cause of mental illness is personal 'weaknesses' (C.M.H.A. 1993; WHO 2001; WHA 2002). This implies blame, that is, any person gripped by mental illness is a weakened person (dispositional attribution), allowing his or her negative thoughts to get out of hand. People who subscribe to this 'weakness' theory of mental illness believe that with a harder try a person can overcome the emotional or mental disorder he or she is suffering from. That means it is caused by failure to recognize 'cure' in personal strength or willpower.

There is also the misguided perception of mental illness in the 'craziness theory' (situational attribution) that is if a person have mental illness, 
it means he or she is crazy. This hinders some families and individuals from giving help. Even when they witness the symptoms of phobia, panic or depression disabling them, they refuse to go to professionals because they believe they are not crazy (Sharma 1998). But, mental illness and its sufferers have universal characteristics across cultures of the world. These are hallucinations and delusions (WHO 2001). These are what respondents in this study reacted to negatively.

\section{CONCLUSION}

This study has accentuated the belief in Delta State that there is a positive relationship between mental illness and socio-cultural practices. Therefore if the cultural beliefs surrounding psychiatry are unchanged, the attitudes of people towards sufferers will remain far from being favourable as the present study reports. The attention or care the mentally ill receive is far below average.

Consequently, it is recommended that health care providers should uphold the tenets of their profession and refuse to allow obnoxious cultural beliefs interfere with their duties. Also, the Federal, State and Local governments should encourage widespread awareness campaign on the care and destigmatization of mental illness.

\section{REFERENCES}

Adebowale TO, Ogunlesi AO1999. Beliefs and knowledge about actiology of mental illness patients and their relatives. African Journal Med Science, 28: 35-41.

Allport GW 1961. Attitudes. In: K Thomas (Ed): Attitudes and Behaviour. Middlesex: Penguin Books. pp. 3649.

Ayorinde A 1983 Mental Health and Everyday Living: An Insight into Practical Issues of Life. Ibadan: Evans Brothers, pp. $153-161$.

Binitie A 1970. Attitude of Educated Nigerians to Mental Illness. Acta Psychiatrica Scandinarica, 46: 27-46.

Botha UA, Koen L, Niechaus DJH 2006. Perceptions of a South African Schizophrenia population with regards to community attitudes towards their illness. Social Psychology and Psychiatric Epidemiology, 41: 619-623.

Brinn F 2000. Patients with Mental Illness: General
Nurses. Attitudes and Expectations. Nursing Standard, 14(27): 13-19.

Canadian Mental Health Association 1993: Mental Health for Life. CMHA Brochure. Ontario: CMHA

Ewhrudjakpor C 1995. Changing Negative Attitudes of Mental Health Professional Towards Counseling Alcoholics in Delta State. Nigeria. Journal of Educational Research, 2(1): 27-38.

Gureje O, Lasebikan VO, Ephraim-Oluwanuge O, Olley BO, Kola, L 2005. Community Study of Knowledge of and attitude to mental illness in Nigeria. The British Journal of Psychiatry. 186: 436-441.

Heider F 1958. The Psychology of Interpersonal Relations. New York: Wiley.

Jegede AS 2005: The notion of "were" in Yoruba Conception of Mental Illness. Nordic Journal of African Studies, 3(2): 5-9.

Jegede RO 1981. A study of the Role of Socio-cultural Factors in the Treatment of Mental Illness in Nigeria. Social Science Medicine, (15A): 49-54.

Mohammed S, Mohammed Sk 2008. Attitudes towards mental illness in a Malay Army Battalion. Medical Journal of Asia, 7(2): 21-32.

Mohammed, Zubair, Isa, SA, Muktar, HA 2004. Perception and beliefs about mental illness among Karfi Village. Northern Nigeria. Journal of International Health and Human Rights: 4(3): 1-8.

Murphy RS 2002. Stigma is universal but experiences are local. World Psychiatry, 1(28): 67-76.

Paterson B 2006. Newspaper representations of mental illness and the impact of the reporting of events on social policy: the 'framing' of Isabel Schwarz and Jonathan Zito. Journal of Psychiatric and Mental Health Nursing, (13): 294-300.

Sharma CP 1998. Mental Illness is like any other Sickness. African Health Management, 4 (3): 6-9.

Thara R, Srinivasan TN 2000. How stigmatizing is schizophrenia in India? International Journal of Social Psychiatry, 46: 135-141.

Udoh CO 2002. Health and Illness Behaviour. Ibadan. Chris-Rose, pp. 29-48.

Ugwuegbu, DCE 1994. The Beautiful Ones are yet to be born: Inter-Ethnic Acceptance among Nigerian School Children. African Journal for the Psychological Study of Social Issues, 1(1): 5-11.

WHO 2001. Mental Health Care in Developing Countries: A Critical Appraisal of Research Findings. World Health Organization. Technical Report Service, 698: 5-34

World Psychiatric Association 2002. WPA Programme to Advice Stigma and Discrimination because of Schizophreria.

http: \ www.opendoors.com/english/media/vol. 3. pdf. Accessed April 2008.

Zimbardo P, Ebbesen EB 1969. Influencing Attitudes and Changing Behaviour. Reading, Mass: AddisonWesley, pp 567-606. 